\title{
Review of Indigenous Research Methodologies by Bagele Chilisa
}

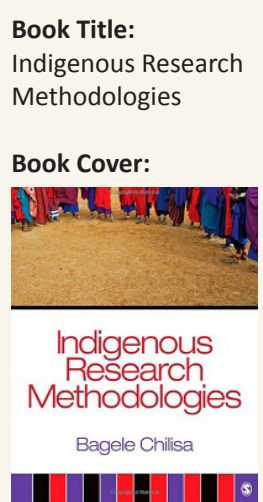

Author:

Bagele Chilisa

ISBN:

9781412958820

Publisher:

SAGE Publications, 2012, R430.00*

*Book price at time of review

\section{Review Title:}

Review of Indigenous

Research Methodologies by

Bagele Chilisa

Reviewer:

Gert Van der Westhuizen ${ }^{1}$

\section{Affiliation:}

${ }^{1}$ Department of Educationa

Psycology, University of

Johannesburg, South Africa

Email:

gertvdw@uj.ac.za

Postal address:

PO Box 524, Auckland Park 6000

How to cite this book review: Van der Westhuizen, G., 2013, 'Review of Indigenous Research Methodologies by Bagele Chilisa', African Evaluation Journal 1(1), Art. \#44, 1 page. http://dx.doi. org/10.4102/aej.v1i1.44

\section{Read online:}

This book by Bagele Chilisa is part of SAGE's series on research methods and evaluation, and can be read as a methodology text, alongside the critical methodology texts by authors such as Smith (Decolonising Methodologies 2012), and Mertens (Transformative Research and Evaluation 2008; Transformative Mixed Methods 2010).

The publication of the text is quite timeous for researchers in South Africa, given the discourses of transformation in society. Since the advent of democracy the project of transformation in education, the social sciences and academia in general has been a priority.

This text is significant as a resource for evaluation researchers and practitioners who are committed to transformation and social justice. In many ways, the book may inspire monitoring and evaluation (M\&E) practitioners to consider ways of working with data that are more responsive to audiences and development agendas. It contains various examples from Chilisa's own research in the social sciences and education. Her examples of completed and published research projects throughout go a long way to concretise the ways in which research methodologies need to be 'decolonised'.

The text consists of ten chapters, covering topics of knowledge systems, the need to be critical of research methodologies, postcolonial, feminist, and indigenous perspectives on research and ways in which specific methods of interviewing may be decolonised. The book closes with a chapter on the implications for the integration of knowledge systems. Structurally, the chapters come full circle, encouraging the reader to think about the problem of knowledge systems and how they are shaped by world views and research practices, how historically they came to be limiting and exclusive, and what needs to be done for such systems to be open and more integrated.

In my reading, the book succeeds in problematising the dilemma shared by researchers internationally who have to draw on mainstream research textbooks to justify their methods: the dominance of Euro-Western research paradigms in most forms of research and evaluation practices in contexts of universities, policy studies, development research and M\&E projects. These traditions of research methodologies are described on the levels of paradigm and philosophical assumptions which should enable the reader as researcher to account for paradigm and methodology choices.

What is particularly useful are the clear descriptions of world views and how they shape research work. This is essentially about who we are as researchers, how we see our roles in society, and how we relate to all participants in research. Bagele's exposition of possible responses to these questions in indigenous paradigms should be intriguing and inviting to researchers in Africa: seeing the role of the evaluator and/or researcher as healer, looking at data about knowledge as relational and holistic, giving prominence to other forms of data (such as folk tales, counter narratives, proverbs, stories, spiritual accounts, etc.; in this regard, valuable exercises and practical examples are included), and practising learning about research from experience so that assumptions and world views may be questioned.

This is the strength of the text: that it can be used as basis to problematise methodologies on the level of philosophical assumptions, to expose the limitations and dominance of Western traditions of research, and to open up space for indigenous knowledge and practice. It will hopefully also encourage researchers and evaluators to problematise issues of sameness, of othering, of objectifying the researched. This is also about research ethics, encouraging considerations of the ethicality of research practice.

The standing of the text has been endorsed by Donna Mertens from Gallaudet University:

‘Bagele Chilisa brings voice to a community of researchers who have much to offer in terms of their rich cultural heritages and expertise in research methodology. She provides an integration of theory and method that has applicability in many contexts. I would recommend this book to anyone who is working in indigenous communities in health, education, international development, or social sciences.'

Copyright: ( 2013. The Authors. Licensee: OpenJournals Publishing. This work is licensed under the Creative Commons Attribution License. 